\title{
Bacterial Spectrum, Isolation Sites and Susceptibility Patterns of Pathogens in Adult Febrile Neutropenic Cancer Patients at a Specialist Hospital in Saudi Arabia
}

\author{
Mansoor Sirkhazi ${ }^{a}$, b, f, Azmi Sarriff ${ }^{\text {, Noorizan Abd Aziz }}$, Fatma Almana ${ }^{a}$, Osama Arafat ${ }^{\mathrm{a}}$, \\ Mahmoud Shorman ${ }^{\mathrm{d}, \mathrm{e}}$
}

\begin{abstract}
Background: Knowing local spectrum and sensitivity for bacterial isolates causing febrile neutropenia is important as starting an appropriate empirical antibiotic therapy is considered a medical emergency in these high-risk patients.
\end{abstract}

Methods: A retrospective study of a total of 106 microbiologically febrile episodes in hospitalized adult neutropenic cancer patients, who were admitted from May 2009 to May 2013, at King Fahad Specialist Hospital, Dammam, Saudi Arabia, was conducted.

Results: Among 106 microbiologically documented febrile neutropenic episodes, the majority of malignancies were solid tumors accounting for $53.8 \%(57 / 106)$ and hematological malignancies accounted for $46.23 \%$ (49/106). The most common malignancies were non-Hodgkin's lymphoma 19.81\% (21/106) followed by acute myeloid leukemia $15.09 \%(16 / 106)$, then colorectal cancer $13.21 \%$ $(14 / 106)$, pancreatic cancer and acute lymphoblastic leukemia accounting for $5.66 \%(6 / 106)$ each, multiple myeloma $4.72 \%(5 / 106)$, gall bladder cancer $3.77 \%(4 / 106)$, and lung cancer $2.83 \%(3 / 106)$. A total of 138 bacterial isolates were identified. The overall prevalence of gram-negative bacteria was $65.94 \%(91 / 138)$ and for grampositive bacteria was $34.06 \%(47 / 138)$. The most common bacterial isolation sites were blood $33.32 \%$ (46 isolates), urine $29.71 \%$ (41 isolates), wound $19.55 \%$ (27 isolates), body fluids $9.41 \%$ (13 isolates) and sputum $7.96 \%$ (11 isolates). The most predominant pathogens were Escherichia coli 30.43 (42/138), Klebsiella pneumonia 14.49\%

Manuscript accepted for publication August 28, 2014

aDepartment of Pharmacy, King Fahad Specialist Hospital, Dammam, Saudi Arabia

${ }^{b}$ School of Pharmaceutical Sciences, University Sains Malaysia, 11800 Minden, Penang, Malaysia

${ }^{c}$ Faculty of Pharmacy, University Technologia MARA, Selengor DE, Malaysia 'Infection Control Department, King Fahad Specialist Hospital, Dammam, Saudi Arabia

'Internal Medicine Department, Marshall University, Huntington, WV 25701, USA

fCorresponding Author: Mansoor Sirkhazi Rahman, Department of Pharmacy, King Fahad Specialist Hospital, Dammam, Saudi Arabia.

Email: mansoor_apc@yahoo.co.uk

doi: http://dx.doi.org/10.14740/wjon850w
(20/138), Staphylococcus aureus 13.04\% (18/138), Sptreptococcus spp. 7.25\% (10/138), Pseudomonas spp. 7.25\% (10/138), Enterococcus spp. 5.80\% (8/138), Staphylococcus spp. 4.35\% (6/138), Corynebacterium spp. $3.62 \%$ (5/138), Enterobacter spp. $3.62 \%$ (5/138), Acinobacter spp. $2.90 \%$ (4/138), Serratia marcescens $2.17 \%$ (3/138), Proteus mirabilis 1.45\% (2). Aeromonas hydrophylia, Citrobacter freundii, Providencia stuartii, Sphingomonas paucimobilis and Stenotropomonas multipholia contributed to $0.72 \%$ with one isolate each. For gram-negative Escherichia coli and Klebsiella pneumonia, the extended-spectrum beta-lactamases producers (ESBLs) rates were $38 \%$ and $22.22 \%$ respectively. For Pseudomonas aerugenosa imipenem-cilastatin resistance rate was $18.84 \%$. For gram-positive bacteria, methicillin-resistant Staphylococcus aureus (MRSA) rate was $28.62 \%$. The vancomycin-resistant Enterococci (VRE) rate was $1.18 \%$.

Conclusion: Gram-negative bacteria were more prevalent as a cause of infection in adult cancer patients with febrile neutropenia at our institution, with Escherichia coli and Klebsiella pneumonia with high ESBLs rates being the most common pathogens. Blood stream infections followed by urinary tract infections were the most common sites of infection. The use of initial antibiotic therapy in febrile neutropenic episodes should be based on local bacterial spectrum and susceptibility/sensitivity patterns to prevent treatment failure with increased morbidity and mortality.

Keywords: Febrile neutropenia; Bacterial isolates; Cancer type and isolation sites

\section{Introduction}

Febrile neutropenia is an adverse effect and serious complications of cytotoxic chemotherapy treatment in cancer patients. Oral temperature $\geq 38.3^{\circ} \mathrm{C}$ or $\geq 38^{\circ} \mathrm{C}$ for more than $1 \mathrm{~h}$, when absolute neutrophill count $<500$ cells $/ \mathrm{mm}^{3}$ or a count of $<$ 1,000 cells $/ \mathrm{mm}^{3}$ with predicted decrease to $<500$ cells $/ \mathrm{mm}^{3}$, are considered as an increased risk of infection and mortality. Fever may be the only manifestation of underlying infections following chemotherapy treatment in cancer patients $[1,2]$. Specific causative pathogens are identified only in $20-25 \%$ of febrile neutropenic patients [3]. 
Table 1. Frequency of Malignancy Type

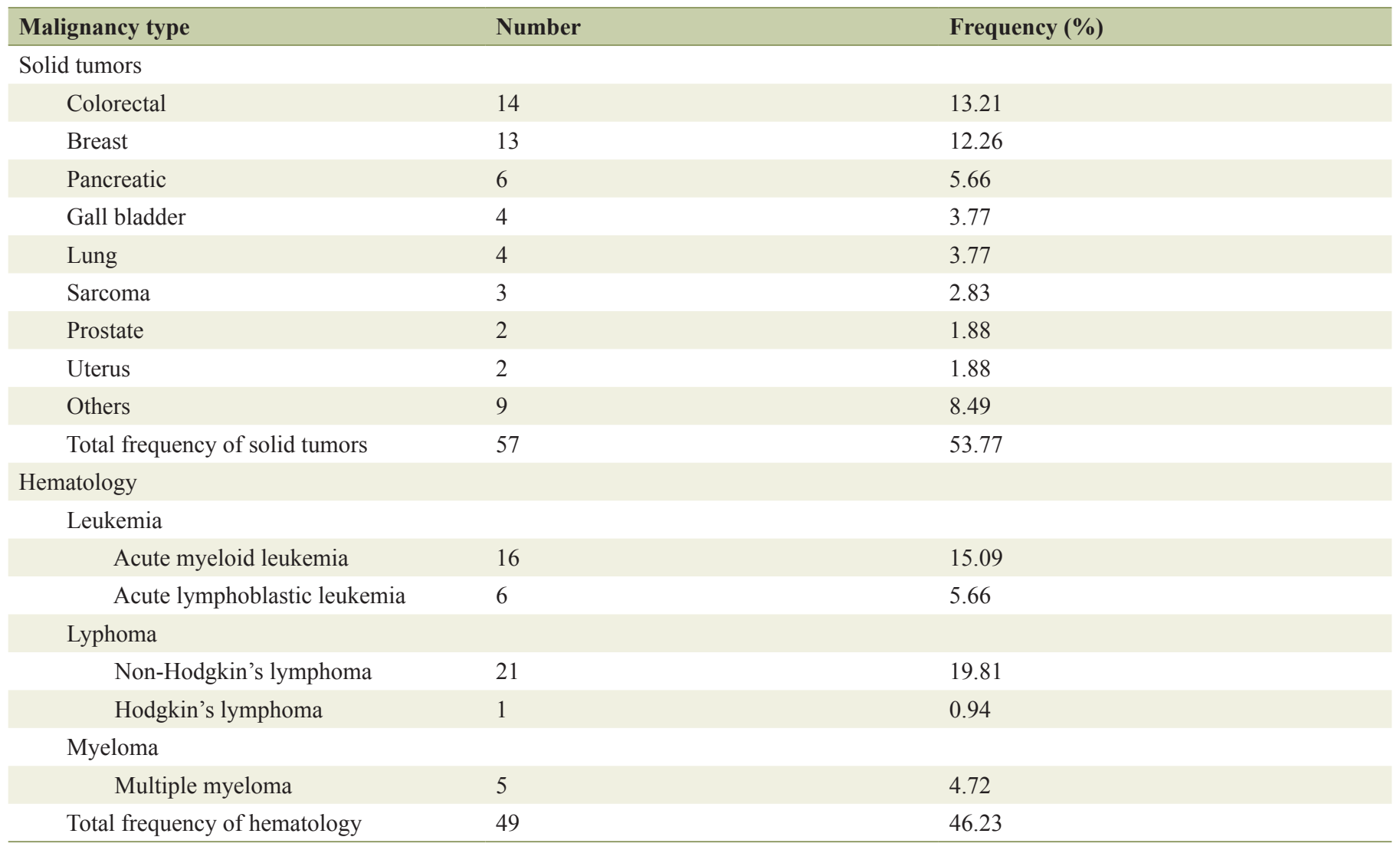

Infection remains the principal complication in netropenic cancer patients. During 1960 s and 1970 s, $80 \%$ of mortality in hematological malignancies was due to infection [4]. Nowadays, the mortality rate is reduced to $20 \%$. The source of bacterial infection in neutropenic patients varies according to the severity and duration of neutropenia [5]. The most common site of infections in neutropenic patients is respiratory tract infections followed by blood stream, urinary tract, skin and soft tissues, oro-pharynx and gastrointestinal tract [4].

In the 1970s gram-negative pathogens were prevailing later in 1980s and 1990s the gram-positive bacteria were emerging [2]. The International American Therapy Cooperative Group (IATCG) of the European Organization for Research and Cancer Treatment of Cancer (EORTC) reported that grampositive pathogens were dominant from 1973 to 1994 and later that same trial observed that the rate of gram-negative bacte-

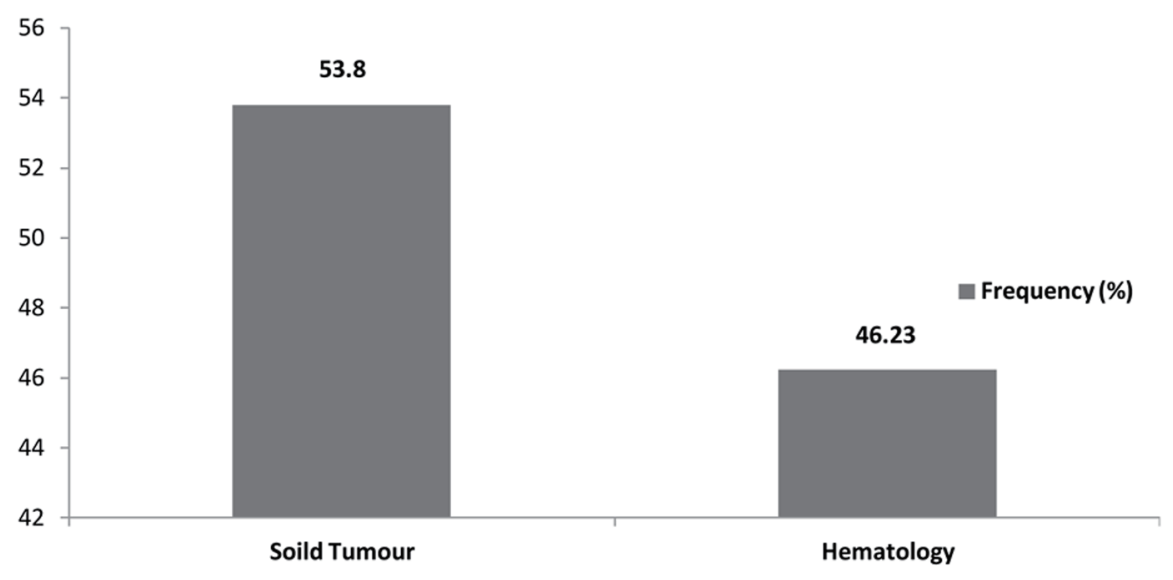

Figure 1. Frequency of type of malignancy. 


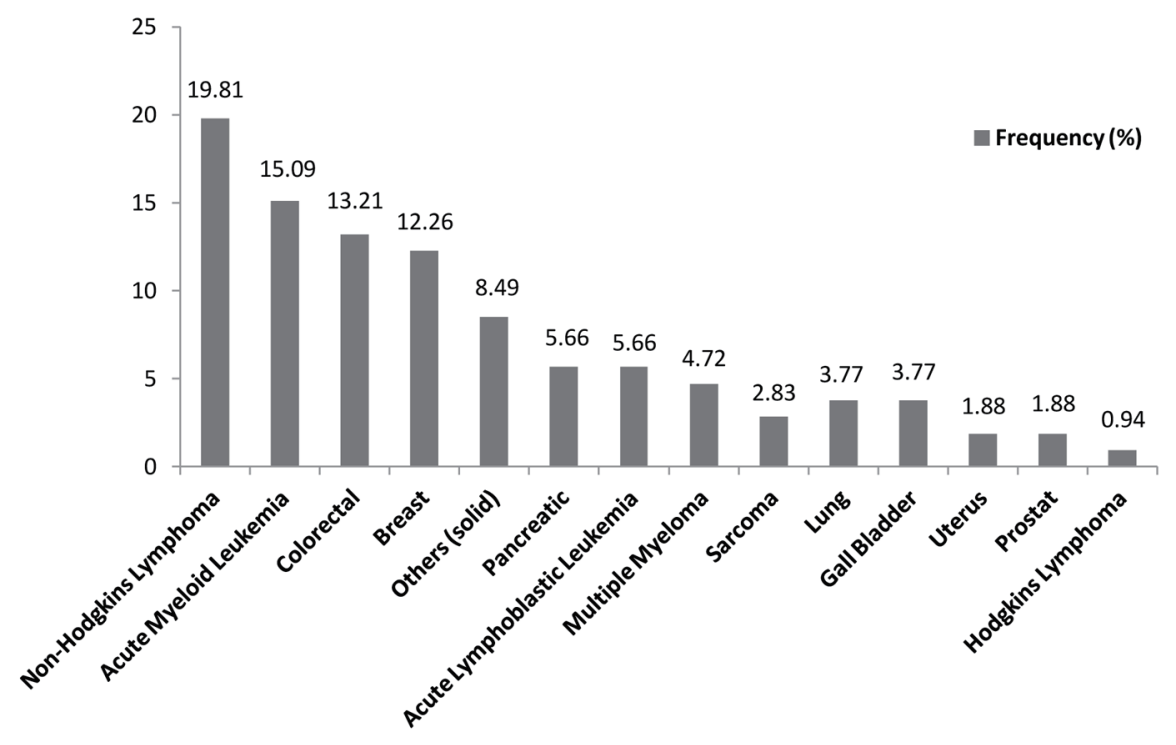

Figure 2. Prevalence of malignancies.

riemias dropped from $71 \%$ to $31 \%$ [6]. Randomized controlled trials conducted by other centers observed the same shifting pattern of the bacterial spectrum in neutropenic cancer patients [7]. The reason for this change in the etiology of pathogens remains unclear [8]. Several studies assumed that the shift of infecting pathogens towards more gram-positive was due to long-term indwelling catheters, aggressive chemotherapy, continuous evolution of antibiotic use and changes in clinical and local antibiotic resistance $[9,10]$.

Recently the etiology of infecting pathogens changed again. Several studies from United States and Europe reported the re-emergence of gram-negative bacteria in neutropenic cancer patients $[9,11]$.

The antimicrobial therapy must be initiated as soon as the infection is suspected in febrile neutropenic patients [4]. Older reports showed that if early empirical antibiotic therapy is not administered, due to gram-negative bacteria in severe neutropenic patients, the mortality rate reached up to $40 \%$. Although later reports showed lower mortality reports but the high mortality justified the initiation of early broad spectrum antibiotics upon the development of fever in these high-risk patients [8].

Over the past two decades, the antibiotic resistance patterns have changed in both gram-positive and gram-negative pathogens that cause infections in febrile neutropenic patients [12]. The emergence of antimicrobial resistance among these pathogens poses new challenges in the management of febrile neutropenic patients. The choice of first-line empiric therapy varies according to local prevalence and bacterial resistance/ susceptibility patterns [13]

In our literature review, we found limited numbers of studies addressing bacterial spectrum, isolation sites and susceptibility patterns in febrile neutropenic patients in Saudi Arabia, and our study is the first comprehensive report to address these issues $[14,15]$.

\section{Methods}

A retrospective study was conducted on the bacterial spectrum, isolation sites and susceptibility patterns of pathogens in adult febrile neutropenic patients hospitalized between May 2009 and May 2013 at the King Fahad Specialist Hospital, a referral hospital providing tertiary care for the Eastern province of Saudi Arabia, with Oncology and Transplant as core competencies. The study was approved by the hospital IRB committee. The patients were included if they met the following inclusion criteria: 1) male and female over the age of 18 years; 2) presence of neutropenia (absolute neutrophil count of $<500$ cells $/ \mathrm{mm}^{3}$ or predicted decrease below 500 cells $/ \mathrm{mm}^{3}$ during the next $48 \mathrm{~h} ; 3$ ) having a single oral temperature measurement of $\geq 38.3{ }^{\circ} \mathrm{C}\left(101{ }^{\circ} \mathrm{F}\right)$ or a temperature of $\geq 38.0{ }^{\circ} \mathrm{C}(100.4$ $\left.{ }^{\circ} \mathrm{F}\right)$ sustained over $1 \mathrm{~h}$ period; 4) having known malignancies; 5) patients with presumed infectious cause of fever were included as high risk. The definition of fever neutropenia was based on the Infectious Diseases Society of America (IDSA) and National Comprehensive Cancer Network (NCCN) clini-

Table 2. Frequency of Gram-Positive and Gram-Negative Pathogens

\begin{tabular}{lllll}
\hline Malignancy type & Gram-positive & Frequency (\%) & Gram-negative & Frequency $(\%)$ \\
\hline Solid tumors & 22 & 28.95 & 54 & 71.05 \\
Hematology & 25 & 40.32 & 37 & 59.68 \\
\hline
\end{tabular}


Table 3. Frequency of Pathogens at Isolated Sites

\begin{tabular}{lllll}
\hline Isolation sites & Gram-positive & \% & Gram-negative & \% \\
\hline Blood & 23 & 16.7 & 23 & 16.7 \\
Urine & 6 & 4.35 & 35 & 12 \\
Wound & 15 & 10.86 & 12 & 8.69 \\
Body fluids & 1 & 0.72 & 9 & 8.69 \\
Sputum & 2 & 1.44 & 6.52 \\
\hline
\end{tabular}

cal guidelines in neutropenic fever in cancer patients. All the data were collected from electronic hospital information system, MedicaPlus. All microbiology reports were as per Clinical and Laboratory Standard Institute (CLSI) guidelines.

\section{Results}

Between May 2009 and May 2013, a total of 106 microbiologically documented infections in febrile neutropenic cancer patients were studied, $53.77 \%(57 / 106)$ of the infections were in patients with solid tumours and $46.23 \%$ (49/106) were in patients with hematological malignancies. The distribution of malignancies showed that non-Hodgkin's lymphoma $19.81 \%$ $(21 / 106)$ was the commonest, followed by acute myeloid leukemia 15.09\% (16/106), colorectal cancer 13.21\% (14/106), breast cancer $12.26 \%$ (13/106) and acute lymphoblastic lymphoma and pancreatic cancer $5.66(6 / 106)$ each (Table 1, Fig. $1,2)$.

\section{Bacterial etiology, sites of isolation and susceptibility pat- tern}

Overall 138 organisms were isolated. In solid tumors, gramnegative organisms accounted for $71.05 \%(54 / 76)$ of the total infections, while gram-positive organisms accounted for $28.95 \%(22 / 76)$ where as in hematological malignancies, gram-negative organisms accounted for $59.68 \%(37 / 62)$, and gram-positive organisms accounted for $40.32 \%(25 / 62)$ (Table 2).

The most common source of bacterial isolation sites was blood stream infections 33.33\% (46/138) followed by urine $29.71 \%$ (41/138), wound $19.56 \%$ (27/138), body fluids $9.42 \%$ (13/138) and sputum 7.97\% (11/138) (Table 3, Fig. 3).

Gram-negative organisms attributed to $16.7 \%(23 / 138)$ of blood stream infections and 25.36\% (35/138) of urinary tract infections while gram-positive organisms accounted for $16.66 \%(23 / 138)$ of the blood stream infections and $10.86 \%$ $(15 / 138)$ of wound infections (Table 3, Fig. 3).

Escherichia coli was the most predominant isolate overall accounting for $30.43 \%$ (42/138), Klebsiella pneumonia accounted for $14.49 \%$ (20/138), Pseudomonas species $7.25 \%$ (10/138), Streptococcus species 7.25\% (10/138), Enterococcus species 5.8\% (8/138) and Staphylococcus aureus $4.35 \%$ (6/138) (Table 4, 5, Fig. 4).

In our study, the majority of pathogens were gram-negative organisms accounting for $65.94 \%(91 / 138)$ of total isolates, while gram-positive organisms accounted for $34.06 \%$ (47/138) (Table 4, 5, Fig. 5).

We examined the susceptibility patterns of the predominant gram-negative and gram-positive pathogens. Among gramnegative pathogens, Escherichia coli showed the following susceptibility patterns: imipenem-cilastatin (99.86\%), amikacin $(91.6 \%)$, piperacillin-tazobactam $(83.15 \%)$ and ceftriaxone $(62.06 \%)$; ESBLs rate was 38\%. While Klebsiella pneumonia showed the following susceptibility patterns: imipenem-cilastatin $(98.96 \%)$, amikacin $(95.24 \%)$, ciprofloxacin $(75.42 \%)$

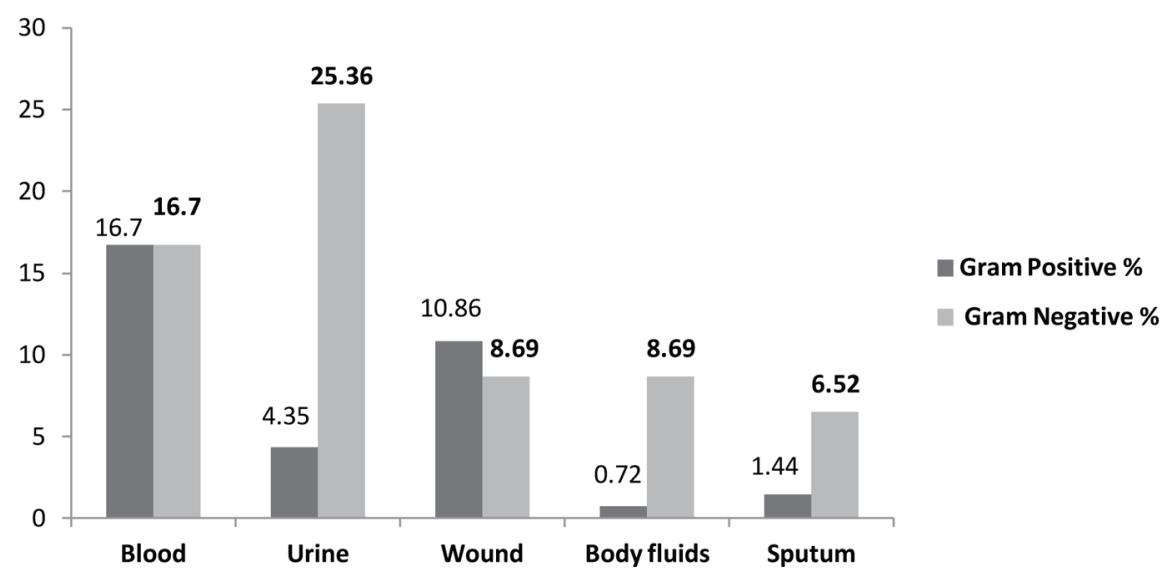

Figure 3. Frequency of pathogens at isolated sites. 
Table 4. Frequency of Gram-Positive Bacterial Isolates in Febrile Neutropenia

\begin{tabular}{|c|c|c|c|c|c|c|}
\hline Gram-positive bacteria & $\begin{array}{l}\text { Blood } \\
\text { culture }\end{array}$ & Urine culture & Sputum culture & Wound culture & $\begin{array}{l}\text { Body fluids } \\
\text { culture }\end{array}$ & Total (\%) \\
\hline Staphylococcus aureus & 5 & - & 1 & 11 & 1 & $18(13.04 \%)$ \\
\hline $\begin{array}{l}\text { Staphylococcus } \\
\text { spp. (CoNS) }\end{array}$ & 4 & 1 & - & 1 & - & $6(4.35 \%)$ \\
\hline Streptococcus spp. & 6 & 2 & 1 & 1 & - & $10(7.25 \%)$ \\
\hline Enterococcus spp. & 4 & 3 & - & 1 & - & $8(5.80 \%)$ \\
\hline Overall frequency & & & & & & $47(34.06 \%)$ \\
\hline
\end{tabular}

and ceftriaxone (77.78\%); ESBLs rate was $22.22 \%$. The Pseudomonas aeruginosa isolates showed the following susceptibility patterns: amikacin $(88.92 \%)$, ciprofloxacin $(82.62 \%)$, piperacillin-tazobactam $(82.28 \%)$ and imipenem-cilastatin (81.16\%). Acinobacter baumanii showed high resistance to ciprofloxacin (65.5\%) and imipenem-cilastatin (56.65\%).

For gram-positive organisms, methicillin-resistant Staphylococcus aureus (MRSA) rate was (28.62\%). Enterococcus showed vancomycin-resistant rate in $1.2 \%$ of isolates. Table 6 summarizes frequency of susceptibility patterns of most frequently used antimicrobials in the empirical treatment of infections in febrile neutropenic patients at King Fahad Specialist Hospital, Dammam, Saudi Arabia.

\section{Discussion}

Infection is a most common complication of chemotherapy, and it causes morbidity and mortality in neutropenic cancer patients. Fever may be the only indication of infection in febrile neutropenia. Bacterial infections are common in this population. In order to treat effectively, the knowledge of likely path- ogens and local bacterial spectrum is very important [16-19].

\section{Trend in shifting of bacterial etiology}

In the past two decades, there was a shift in the etiology of bacterial infections in febrile neutropenic patients towards grampositive organisms accounting for as much as $70 \%$ in various reports [7]. The cause of this change in etiology is unclear. This change might be due to long-term use of indwelling catheters, radiation therapy, widespread use of flouroquinolones and aggressive chemotherapy leading to mucosal damage and increasing the risk of infection $[6,7,10]$. The nature of chemotherapy used also influences bacterial etiology. The regional climatic or environmental conditions also influence changes in bacterial spectrum. Pseudomonas aerugenosa are more predominant in warmer climates [9].

Recently, the bacterial etiology has changed again from gram-positive to gram-negative organisms. Many studies from different parts of the world showed this change of trend $[5,11$, 18, 20-22] and only one small study from Saudi Arabia looked at the pattern of febrile neutropenia presentations in solid tu-

Table 5. Frequency of Gram-Negative Isolates in Febrile Neutropenia

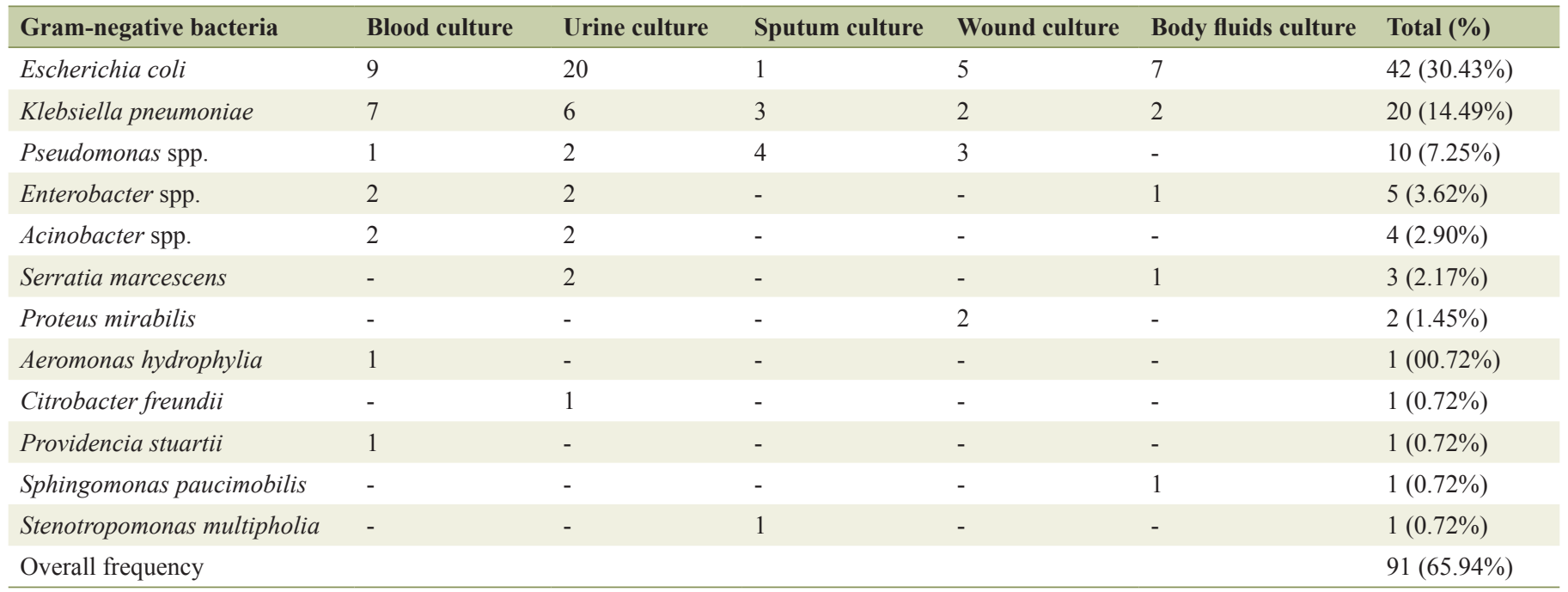




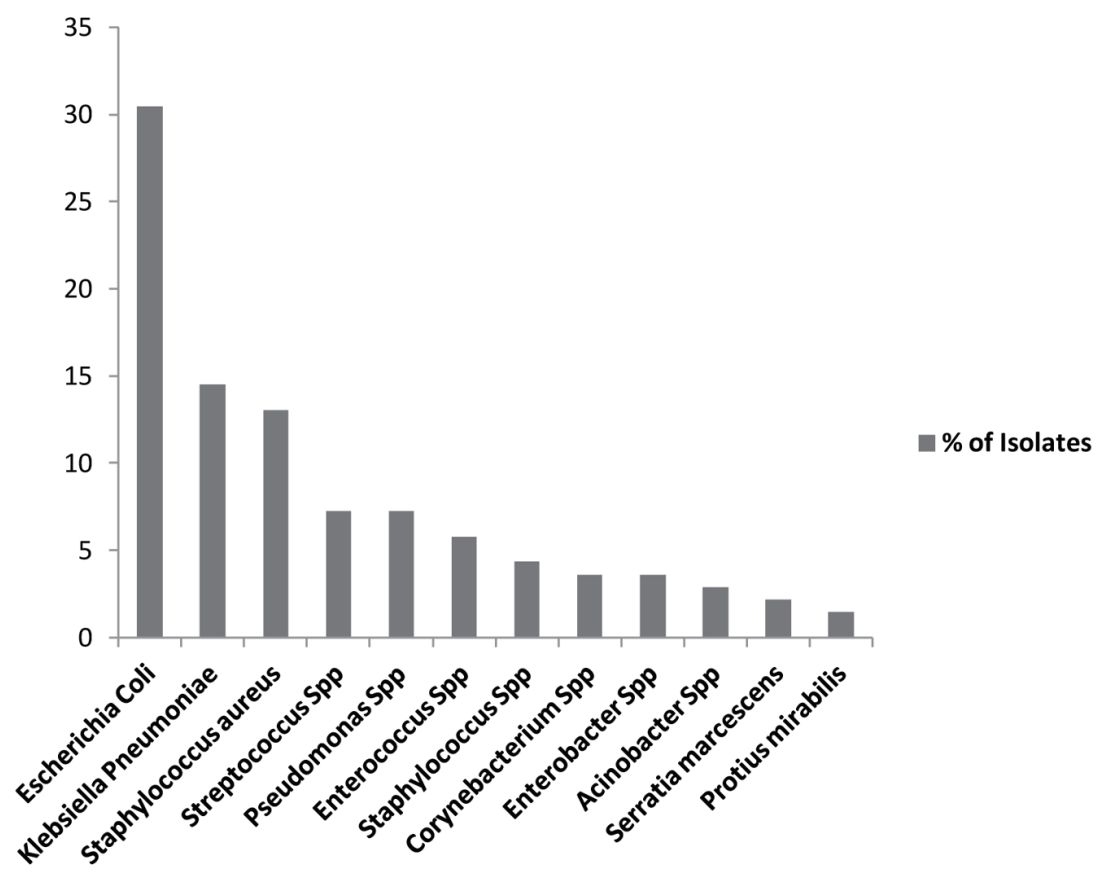

Figure 4. Prevalence of pathogens in febrile neutropenia.

mors $[14,15]$.

In our study of the etiology of bacterial infections in febrile neutropenic patients, gram-negative pathogens (65.94\%) accounted for almost two-thirds of bacterial infections whereas gram-positive organisms were identified in $34.06 \%$. Our findings are similar to other studies in our geographical region, pointing to the importance of covering gram-negative organisms empirically according to the most likely pathogens, and local sensitivity data in this high-risk group of patients $[16$, 18].

Our data provide a greater emphasis on the importance of local data in managing patients as described in the literature and a combination of an antipseudomonal beta-lactam agent and an aminogylcoside empirical regimen was adapted in our hospital according to our data; vancomycin was added for patients with MRSA risk factors.

\section{Site of bacterial isolation}

There are many studies showing the importance of geographical location in bacterial isolation sites $[2,18,21,23]$. In the

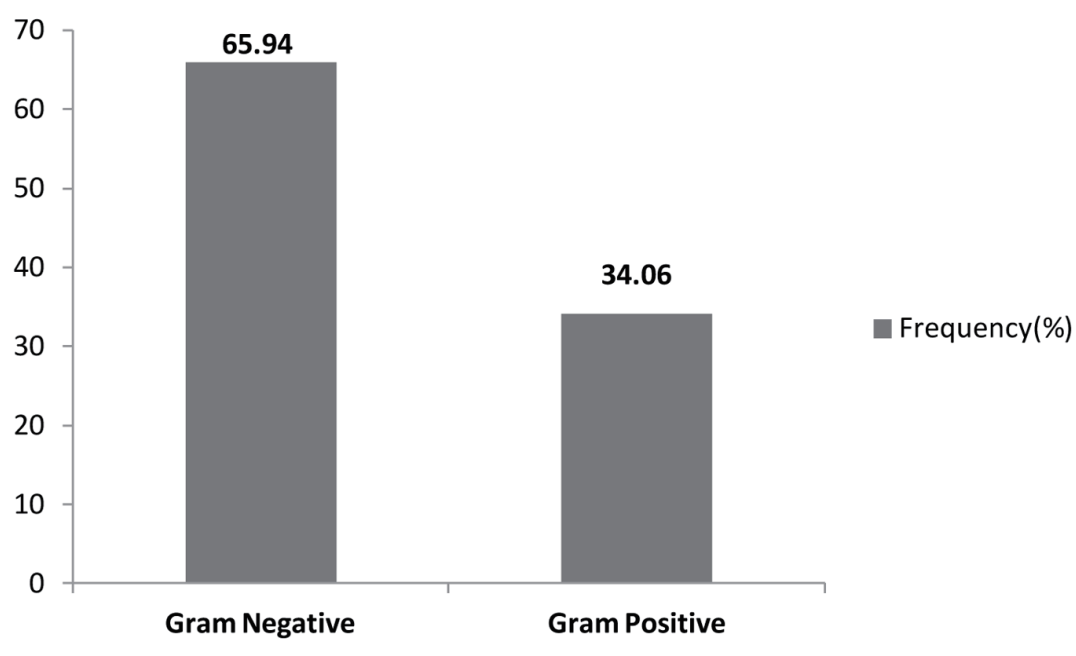

Figure 5. Overall frequencies of bacterial isolates. 


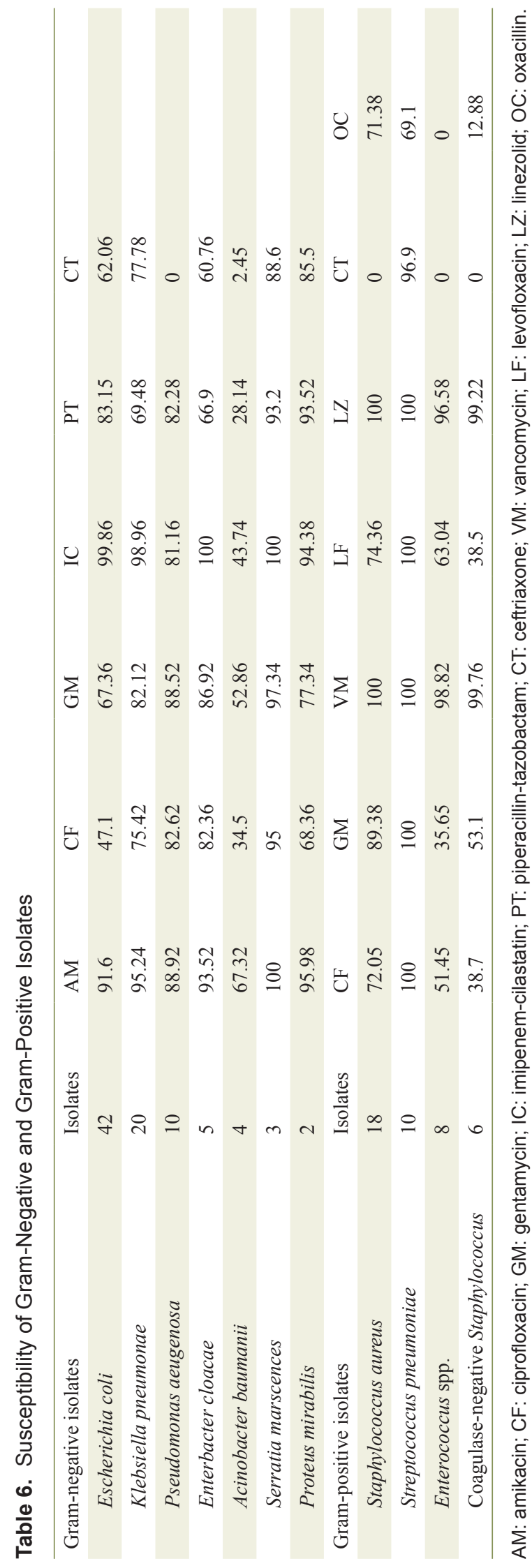

published literature, the most common bacterial isolation sites in patients with febrile neutropenia were blood stream, urine, wound, respiratory tract, gastrointestinal tract and skin and soft tissues [7, 22, 24].

Our study showed similar trends of site of isolation as discussed in the above studies. The most predominant isolation sites were blood stream $33.32 \%$, urine $29.71 \%$, wounds $19.55 \%$, body fluids $7.96 \%$, and from sputum $7.96 \%$.

\section{Susceptibility patterns}

Extended-spectrum $\beta$-lactamase (ESBL)-producing bacteria have become a serious problem in many different geographical regions. Carbapenems are the corner stone of treatment for these organisms, and because of its increase usage for empirical therapy, the risk of selecting resistant organisms is increasing (carbapenem-producing organisms). Many centers are also reporting increased rates of multidrug-resistant gram-negative bacteria such as Acinobacter and Pseudomonas aerugenosa, which makes treatment of these infections more difficult [25]. Studies also reported the increased rates of gram-positive resistant pathogens in many centers, especially MRSA and VRE [26].

In our study we found high rates of ESBLs among $E s$ cherichia coli (38\%) and Klebsiella pneumonia $(22.22 \%)$ and increased imipenem-cilastatin resistance among Pseudomonas aerugenosa $(18.84 \%)$; MRSA rate was $28.72 \%$. This higher than reported rate of ESBLs in our hospital compared to the published rates in the region is probably due to the nature of our high-risk cancer patients, recurrent hospitalizations, and prior use of antimicrobials and the increased use of antibiotics for prophylaxis especially flouroquinolones [27].

\section{Conclusions}

In conclusion, our study shows similar results with international studies in overall prevalence of gram-negative organisms and their isolation sites but different trends in bacterial etiology and susceptibility patterns. Local data for bacteria causing infections in febrile neutropenic patients are needed to help in selecting appropriate empirical antimicrobial therapy.

\section{References}

1. Freifeld AG, Bow EJ, Sepkowitz KA, Boeckh MJ, Ito JI, Mullen CA, Raad, II, et al. Clinical practice guideline for the use of antimicrobial agents in neutropenic patients with cancer: 2010 update by the infectious diseases society of america. Clin Infect Dis. 2011;52(4):e56-93.

2. Meidani M, Bagheri A, Khorvash F. A Population-Based Study of Bacterial Spectrum in Febrile Neutropenic Patients. Jundishapur J Microbiol. 2013;6:150-156.

3. Nesher L, Rolston KV. The current spectrum of infection in cancer patients with chemotherapy related neutropenia. Infection. 2014;42(1):5-13. 
4. Glauser M. Empiric therapy of bacterial infections in patients with severe neutropenia. Diagn Microbiol Infect Dis. 1998;31(3):467-472.

5. Rasool Hassan BA, Yusoff ZB, Othman SB. Fever/clinical signs and association with neutropenia in solid cancer patients--bacterial infection as the main cause. Asian Pac J Cancer Prev. 2010;11(5):1273-1277.

6. Swati M, Gita N, Sujata B, Farah J, Preeti M. Microbial etiology of febrile neutropenia. Indian J Hematol Blood Transfus. 2010;26(2):49-55.

7. Purewal SS, Singh RP, Kahlon RS. Study of Bacterial Pathogens and Viral Infections in Neutropenic Cancer Patients.

8. Viscoli C, Castagnola E. Planned progressive antimicrobial therapy in neutropenic patients. Br J Haematol. 1998;102(4):879-888.

9. Ramphal R. Changes in the etiology of bacteremia in febrile neutropenic patients and the susceptibilities of the currently isolated pathogens. Clin Infect Dis. 2004;39(Suppl 1):S25-31.

10. Viscoli C, Varnier O, Machetti M. Infections in patients with febrile neutropenia: epidemiology, microbiology, and risk stratification. Clin Infect Dis. 2005;40(Suppl 4):S240-245.

11. Walwyn M, Nicholson A, Lee MG, Wharfe G, Frankson MA. Febrile neutropaenia in cancer patients. West Indian Med J. 2010;59(2):209-214.

12. Wisplinghoff H, Bischoff T, Tallent SM, Seifert H, Wenzel RP, Edmond MB. Nosocomial bloodstream infections in US hospitals: analysis of 24,179 cases from a prospective nationwide surveillance study. Clin Infect Dis. 2004;39(3):309-317.

13. Irfan S, Idrees F, Mehraj V, Habib F, Adil S, Hasan R. Emergence of Carbapenem resistant Gram negative and vancomycin resistant Gram positive organisms in bacteremic isolates of febrile neutropenic patients: a descriptive study. BMC Infect Dis. 2008;8:80.

14. Al-Ahwal MS. Pattern of febrile neutropenia in solid tumors-A hospital based study. Pak J Med Sci. 2005;249252.

15. Al-Ahwal MS, Al-Sayws F, Johar I. Febrile neutropenia comparison between solid tumours and hematological malignancies. Pan Arab Med J. 2005;4:4-7.

16. al-Bahar S, Pandita R, Dhabhar BN, al-Bahar E. Febrile neutropenia in cancer patients in Kuwait: microbial spectrum and outcome. Support Care Cancer. 1994;2(6):400402.

17. Hughes WT, Armstrong D, Bodey GP, Bow EJ, Brown
AE, Calandra T, Feld R, et al. 2002 guidelines for the use of antimicrobial agents in neutropenic patients with cancer. Clin Infect Dis. 2002;34(6):730-751.

18. Kanafani ZA, Dakdouki GK, El-Chammas KI, Eid S, Araj GF, Kanj SS. Bloodstream infections in febrile neutropenic patients at a tertiary care center in Lebanon: a view of the past decade. Int J Infect Dis. 2007;11(5):450453.

19. Meir HM, Balawi IA, Meer HM, Nayel H, Al-Mobarak MF. Fever and granulocytopenia in children with acute lymphoblastic leukemia under induction therapy. Saudi Med J. 2001;22(5):423-427.

20. Baskaran ND, Gan GG, Adeeba K, Sam IC. Bacteremia in patients with febrile neutropenia after chemotherapy at a university medical center in Malaysia. Int $\mathrm{J}$ Infect Dis. 2007;11(6):513-517.

21. Burney IA, Farooqui BJ, Siddiqui T, Khurshid M. The spectrum of bacterial infections in febrile neutropenic patients: effect on empiric antibiotic therapy. J Pak Med Assoc. 1998;48(12):364-367.

22. Yadegarynia D, Fatemi A, Mahdizadeh M, Kabiri Movahhed R, Alizadeh MA. Current spectrum of bacterial infections in patients with nosocomial fever and neutropenia. Caspian J Intern Med. 2013;4(3):698-701.

23. Erikci AA, Ozturk A, Ozyurt M, Tekgunduz AE, Karagoz B, Bilgi Ou, et al. Febril Neutropenia Etiology In A Hematology Department. European Journal of General Medicine. 2008;5(4):228-231.

24. Karanwal AB, Parikh BJ, Goswami P, Panchal HP, Parekh BB, Patel KB. Review of clinical profile and bacterial spectrum and sensitivity patterns of pathogens in febrile neutropenic patients in hematological malignancies: A retrospective analysis from a single center. Indian J Med Paediatr Oncol. 2013;34(2):85-88.

25. Alp S, Akova M. Management of febrile neutropenia in the era of bacterial resistance. Ther Adv Infect Dis. 2013;1(1):37-43.

26. Morris PG, Hassan T, McNamara M, Hassan A, Wiig R, Grogan L, Breathnach OS, et al. Emergence of MRSA in positive blood cultures from patients with febrile neutropenia--a cause for concern. Support Care Cancer. 2008;16(9):1085-1088.

27. Khanfar HS, Bindayna KM, Senok AC, Botta GA. Extended spectrum beta-lactamases (ESBL) in Escherichia coli and Klebsiella pneumoniae: trends in the hospital and community settings. The Journal of Infection in Developing Countries. 2009;3(4):295-299. 